\title{
The profile of CT scan findings in acute head trauma in Orotta Hospital, Asmara, Eritrea
}

\author{
${ }^{1}$ Mebrahtu-Ghebrehiwet MD, ${ }^{2}$ Liu Hai Quan MD, ${ }^{3}$ Tsighe Andebirhan MD \\ Institutional Affiliation of the Authors \\ 'Radiologist, Orotta National Referral Hospital, Asmara, Eritrea \\ ${ }^{2}$ Neuro Radiologist, Henan Zhong Liu Hospital, Hanan, China \\ ${ }^{3}$ Pediatrician, Orotta National Referral Hospital, Asmara, Eritrea \\ Correspondence to be sent to: \\ Mebrahtu Ghebrehiwet MD
}

Abstract

Background: There are variations in outcomes of radiological investigations of head injuries in different studies from different countries. The use of investigation modalities are influenced by socioeconomic and cost effectiveness of the tests.

Objective and methods: The purpose of the present five months observational study was to describe the profile of cranial computed tomography (CT) scan findings of 110 cases of acute head trauma in Orotta Hospital.

Results: The mean age of the entire series was 32.5 years with SD of 20.9 years. The overall male to female ratio was 3:1. The commonest causes of head injury were falls (36.4\%), car accident (29.0\%), stone injuries (15\%), and bicycle accident (9\%). Abnormal CT findings were seen in 60 cases (54.5\%) and normal CT in 50 (45.5\%). The most common CT findings were: intra cerebral hematoma 22 (20. \%), cerebral contusion or laceration $18(16.4 \%)$, skull fractures $16(6 \%)$, and scalp swelling 3 (2.7\%).

Conclusion: The high prevalence of head trauma related CT findings justify the use of CT in acute head trauma in Eritrea. However; it should be done only when clinically indicated in order to reduce cost and avoid unnecessary irradiation.

\section{Introduction}

Head Injury is considered as a major health problem that is a frequent cause of death and disability and makes considerable demands on health services. In developing countries accident rates in general and traumatic brain injury in particular are increasing as traffic increases besides other factors like industrialization, falls and ballistic trauma. ${ }^{1}$ Head injury refers to any damage to the scalp, skull, or brain. There are two general categories of head injuries: closed and penetrating. A closed injury is one in which the skull is not broken open. In penetrating injury, the skull is broken open. Closed head injury is the result of variety of mechanisms including motor vehicle and motor cycle accidents, falls from heights, assaults and pedestrians being struck by motor vehicles. Penetrating injury is most often due to gunshots but some times other types of blunt objects can violate the skull. Most commonly, traumatic brain injury occurs in the presence of additional injuries to other major organ systems, but it can occur in isolation. ${ }^{2}$

Traumatic head injury is a leading cause of death and disability in children and adults in their most productive years.Traumatic head injury is an increasing health problem globally and especially in Eritrea. In Eritrea the morbidity and mortality due to head injury is on the rise. During the study period the morbidity of head injury in Orotta Hospital in 2006 and 2007 was $27536(2.6 \%)$ and 31935 (2.7\%), respectively, with annual increase of $0.1 . \%$. The total Death due to head injury in 2006 and 2007 was 245 (10\%) and 352 (13.3\%). ${ }^{5}$ With the constant increase in high velocity accidents and violence over the past decades, the matter of acute head trauma is one of prime importance in today's medical practice. ${ }^{6}$ The morbidity and mortality associated with significant intracranial injury may be ameliorated by early diagnosis and treatment.? Despite the frequent occurrence of head injury, diagnostic strategies differ among individuals and institutions.

Historically, imaging of head-injured patient relied on skull radiographs. with the wide spread availability and advancement of head CT scanning, the CT scan has become the diagnostic procedure of choice when evaluating acute head trauma. ${ }^{3}$ Magnetic resonance offers, no advantage over CT in the acute evaluation of head trauma. MRI may be useful in the evaluation of patients with a normal CT but persistently abnormal clinical signs ${ }^{8}$. In Eritrea skull radiography has been used as part of the evaluation for every head trauma case, as CT is still a scarce resource in Eritrea it is reserved for severely injured patients. In Orotta Hospital, CT is recurrently recommended for all admitted patients and some outpatients with acute head trauma. The purpose of the study is to describe the profile of head injury in Orotta Hospital depicting causal factors, age and gender distribution, and CT findings related to acute head trauma.

\section{Materials and Methods}

The study was conducted at Orotta medical surgical Hospital, Asmara, Eritrea from January up to March 2006 and from November up to December 2007. One hundred ten consecutive post-traumatic CT of the head were performed over a five month period. The CT scan which were done from 2 hours up to 30 days after trauma, that deals primarily with acute and sub acute cases, were included in the study.

All studies were performed with a single CT scanner (Tomoscan CX/Q Philips medical systems, Philips) and a protocol of contiguous axial 5-mm sections through the posterior fossa and a contiguous axial10-mm 
sections to the vertex. Brain (window width, $80 \mathrm{HU}$;

Figure 2: Causes of trauma distributed by gender

level, $40 \mathrm{HU}$ ), subdural (width, $350 \mathrm{HU}$; level, $40 \mathrm{HU}$ ), and bone (width, $3500 \mathrm{HU}$; level, 500 $\mathrm{HU})$ windows were scanned in each patient. No contrast material was administered. For each patient who under went trauma related $C T$, the $C T$ technologist recorded the patient information in the registration book.

The following Information was documented at the time of initial visit: age, gender, referring Hospital, clinical signs and symptoms, duration of head injury, nature of head injury (scalp, skull, intracranial); mode of injury (fall, road traffic accident, stone injury), CT findings, condition at presentation. Treatment received and outcome of the treatment were not studied. Data was

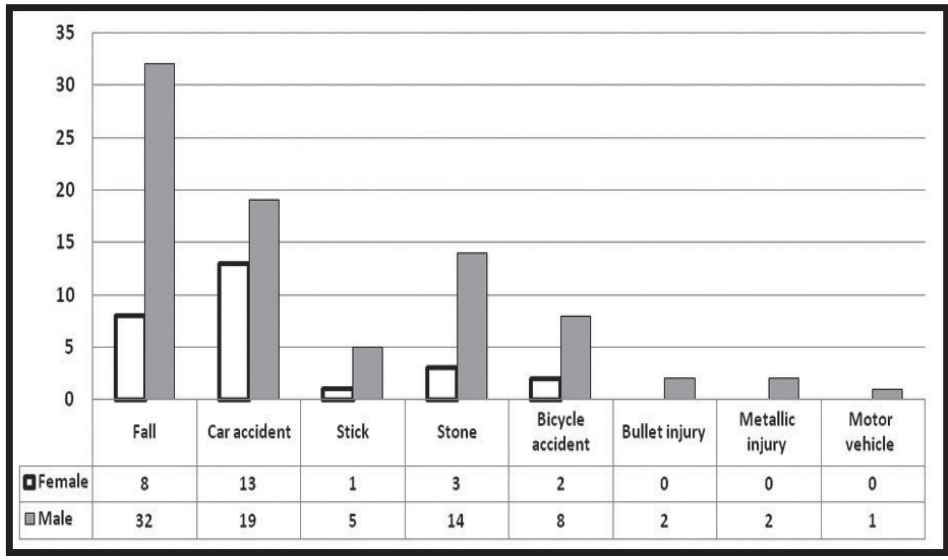
entered in excel where it is exported into statistical package for social science software (SPSS) version 12.0.

\section{Results from the study}

Eighty three $(75.5 \%)$ patients were male and 27 (24.5\%) were female (Sex ratio M: F = 3:1). Ages ranged from one year to 80 Years, with a mean age of 32.5years with SD 20.9. The highest frequency of head trauma occurred in the 21-30 year group (22.7\%), followed by the age groups $11-20$ years (20\%) and $31-40$ years (14.5\%) (See Figure 1).

Figure 1: Age and sex distribution of the 110 head trauma patients

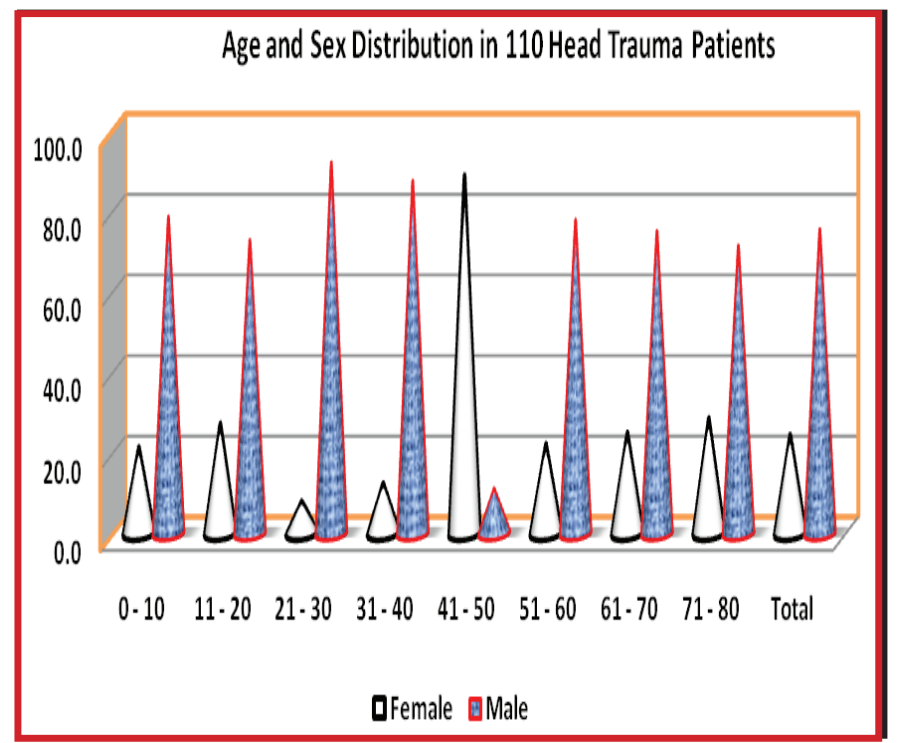

Table 1: Causes of trauma according to age and gender

\begin{tabular}{|l|l|c|c|c|c|c|c|c|c|c|}
\hline $\begin{array}{l}\text { S/ } \\
\text { N }\end{array}$ & $\begin{array}{l}\text { Types of } \\
\text { accident }\end{array}$ & \multicolumn{2}{|c|}{ Female } & \multicolumn{2}{|c|}{ male } & $\begin{array}{c}\text { Mean } \\
\text { age }\end{array}$ & $\begin{array}{c}\text { Sex } \\
\text { ratio }\end{array}$ & \multicolumn{2}{|c|}{$\begin{array}{c}\text { St. Dev } \\
\text { iation }\end{array}$} & \multicolumn{2}{|c|}{ Number } \\
\hline & & $\#$ & $\%$ & $\#$ & $\%$ & & & & $\#$ & $\%$ \\
\hline 1 & Fall & 8 & 29.6 & 32 & 38.6 & 31.6 & 4.0 & 2.9 & 40 & 36.4 \\
\hline 2 & $\begin{array}{l}\text { Car } \\
\text { accident }\end{array}$ & 13 & 48.1 & 19 & 22.9 & 32.9 & 1.5 & 2.5 & 32 & 29.1 \\
\hline 3 & Stick & 1 & 3.7 & 5 & 6.0 & 43.3 & 5.0 & 3.3 & 6 & 5.5 \\
\hline 4 & Stone & 3 & 11.1 & 14 & 16.9 & 24.5 & 4.7 & 2.7 & 17 & 15.5 \\
\hline 5 & $\begin{array}{l}\text { Bicycle } \\
\text { accident }\end{array}$ & 2 & 7.4 & 8 & 9.6 & 42.0 & 4.0 & 3.1 & 10 & 9.1 \\
\hline 6 & $\begin{array}{l}\text { Bullet } \\
\text { injury }\end{array}$ & 0 & 0.0 & 2 & 2.4 & 49.5 & - & 3.2 & 2 & 1.8 \\
\hline 7 & $\begin{array}{l}\text { Metallic } \\
\text { injury }\end{array}$ & 0 & 0.0 & 2 & 2.4 & 26.0 & - & 2.3 & 2 & 1.8 \\
\hline 8 & $\begin{array}{l}\text { Motor } \\
\text { vehicle }\end{array}$ & 0 & 0.0 & 1 & 1.2 & 11.0 & - & 2.8 & 1 & 0.9 \\
\hline & Total & 27 & 100 & 83 & 100 & 32.5 & 3.1 & 20.9 & 110 & 100 \\
\hline
\end{tabular}

Table 2 shows that of the 110 patients studied 6 different lesions related to head trauma were detected on CT Scans. Hematoma was the most common findings $22(20.0 \%)$, followed by cerebral contusion or laceration 18 (16.4\%). 16 (14.6\%) patients were with skull fracture both linear and depressed fracture, only $3(2.7 \%)$ were with scalp swelling. Hematomas were further subdivided as follows. 14 (63.6\%) were subdural hematoma, followed by epidural hematoma 4 (18.2\%), inter ventricular hematoma $2(9.1 \%)$ \& subarachinoid Hemorrhage 2 (9.1\%) .

As shown in Figure 2, the most common causes of head injury were falls (36.4\%), car accidents 29.0 $\%$, stone injuries (15\%) and bicycle accidents (9\%). Moreover, table 1 shows that 26. 4\% of the patients were less than 16 years of age and $73.6 \%$ were greater than 16 years of age. The medium age for each group of cause varied from 11- 49.5 to years. The same table shows that there was difference in the distribution of causes according to age and gender. (Table1).

\begin{tabular}{|l|l|c|c|}
\hline \multicolumn{4}{|c|}{ Table 2: CT findings of the patients } \\
\hline S/N & Type of injury/lesion & $\begin{array}{l}\text { Freq } \\
\text { uency }\end{array}$ & $\begin{array}{l}\text { Per } \\
\text { cent }\end{array}$ \\
\hline 1 & Scalp swelling/injury & 3 & 2.7 \\
\hline 2 & Skull fracture (fracture of bone) & 8 & 7.3 \\
\hline 3 & Cerebral contusion or laceration & 18 & 16.4 \\
\hline 4 & Depressed fracture & 8 & 7.3 \\
\hline 5 & Hematoma & 22 & 20.0 \\
\hline
\end{tabular}




\begin{tabular}{|l|l|l|l|}
\hline 6 & FBS in brain & 1 & 0.9 \\
\hline 7 & Normal finding & 50 & 45.5 \\
\hline & Total & 110 & 100 \\
\hline & Sub-Heamatoma & & \\
\hline & 5.1 Epidural Hematoma & 4 & 18.2 \\
\hline & 5.2 Subdural Hematoma & 14 & 63.6 \\
\hline & 5.4 Inter-ventricular Hematoma & 2 & 9.1 \\
\hline & $\begin{array}{l}5.5 \text { Sub-arachnoids } \\
\text { Hemorrhage }\end{array}$ & 2 & 9.1 \\
\hline
\end{tabular}

Table 3 shows that patients were more likely to have a positive finding if the injury was sustained from bicycle accident (90\%) and car accidents (62.5\%.) Chisquare tests done showed that the causes of head trauma were found to be linearly associated with the $C T$ finding at $(P<0.048)$.

\begin{tabular}{|l|l|c|c|c|}
\hline \multicolumn{4}{|c|}{ Table 3: Type of injuries vs. CT finding } \\
\hline \multicolumn{2}{|c|}{} & \multicolumn{2}{|c|}{ CTFindings_2 } & Total \\
\cline { 3 - 4 } \multicolumn{2}{|l|}{} & Positive & Negative & \\
\hline $\begin{array}{l}\text { Type of } \\
\text { injury }\end{array}$ & Fall & 15 & 25 & 40 \\
\hline & Car accident & 20 & 12 & 32 \\
\hline & Stick & 3 & 3 & 6 \\
\hline & Stone & 10 & 7 & 17 \\
\hline & Bicycle accident & 9 & 1 & 10 \\
\hline & Bullet injury & 2 & 0 & 2 \\
\hline & Metallic injury & 1 & 1 & 2 \\
\hline & Motor vehicle & 0 & 1 & 1 \\
\hline Total & & 60 & 50 & 110 \\
\hline
\end{tabular}

Table 4 shows that the incidence of positive CT findings was high in patients with weakness of extremities and hemiplegia and in the unconscious patients. CT done for head aches; dizziness nausea and vomiting were of less diagnostic value. Chi -square test shows that there was statistically significant association between the clinical signs and $C T$ findings $(P<0.026)$.

\begin{tabular}{|l|c|c|c|}
\hline \multicolumn{4}{|l|}{ Table 4: Clinical finding vs. CT Findings } \\
\hline Clinical findings. & \multicolumn{2}{|l|}{ CT Findings. } & Total \\
\hline Head ache + Dizziness & Positive & Negative & \\
\hline Nausea + Vomiting & 16 & 14 & 22 \\
\hline $\begin{array}{l}\text { Loss of consciousness/ } \\
\text { unconsciousness + Coma }\end{array}$ & 14 & 4 & 18 \\
\hline $\begin{array}{l}\text { Confusion/disorientation + } \\
\text { Restlessness }\end{array}$ & 12 & 16 & 28 \\
\hline $\begin{array}{l}\text { Weakness of extremities + } \\
\text { hemiplegia }\end{array}$ & 10 & 3 & 13 \\
\hline Total & 60 & 50 & 110 \\
\hline
\end{tabular}

\section{Discussion}

Head injury is a universal problem affecting relatively young people in general and male sex in particular. In our study the age of patients varied from 1 year to 80 years. Majority of patients found to be in third decade of life. The second highest age group was in second decade followed by fourth decade. These three age groups are the most active groups of society who spend most of their time out of their houses for education and to earn the livelihood are more prone to accidents.

A steady decline was also noted after the age of 40 years. Patients above the age of 60 years were rather less mobile and therefore unlikely to get involved in road traffic accidents.

The male: female ratio of 3:1 observed in this study is a common trend in previous reports. Most of the USA reports show an incidence ratio of $>2: 1$ for males compared to females. ${ }^{9}$ The reason for male predominance is that males move out of their homes more frequently and are more actively working than females. Our series showed fall accidents as a major cause of head trauma. In similar studies in Brazil aggression which includes assaults and fire arm injuries were the commonest cause of head trauma ${ }^{10}$. Other series showed automobile accidents as a major cause of head trauma. In the USA, more than one third of causes were related to automobile accidents ${ }^{11}$ which is comparable to findings from our study.

A study in Ghana and another in Nigeria showed road traffic accidents were the commonest causes of head injury ${ }^{12,13}$. Our findings are thus not in keeping with the above mentioned literature. In our series 60 (54.5\%) of 110 patients presented positive CT findings related to acute trauma. Studies in Brazil, presented positive CT findings in a quarter of cases mild head trauma ${ }^{10}$ while in Ghana the proportion nearly half of the cases with positive CT findings ${ }^{12}$.

A study in Nigeria, ${ }^{13}$ in patients with moderate to severe head injury shows $87 \%$ patients had abnormal CT findings. It is conceivable that methodological differences among those studies and ours may account for such different proportions. Regarding, lesion types, intracerebral hematoma was the most common finding. Bordingon et al ${ }^{10}$ and Jeret et $\mathrm{al}^{14}$ found less than $10 \%$ among mild head trauma patients. What probably explains our higher number of intracerebral hematoma was that we included all patients with acute trauma (mild to severe injury). Our study found $14(63.6 \%)$ subdural hematoma, 4 (18.2\%) epidural hematoma. 2 (9. \%) inter ventricular hematoma and 2 (9.1\%) subarachinoid hemorrhage. The sensitivity of CT in detecting intracranial hemorrhage is noted in this study. Cerebral contusions were seen in $12.9 \%{ }^{10}$.

The present study showed similar proportions of symptoms associated with positive CT scans, have included headache, dizziness, nausea, vomiting loss of consciousness, weakness of extremities and hemiplegia. The incidence of CT findings was high in patients with weakness of extremities and hemiplegia and in the unconscious patients. CT donefor headaches; dizziness and vomiting were of less diagnostic value. 
Our finding is similar to other previous studies in Africa and USA. ${ }^{(12,6)}$ The correlation between the severity of clinical presentations and the number and intensity of abnormalities visualized at computerized tomography showed a linear relationship and again one can expect a larger number of lesions and more severe abnormalities as the severity of clinical presentation increases.

\section{Conclusion}

Injuries from accidental falls played a major role as cause of head trauma. Car accident still has a great importance. The high prevalence of head trauma related $C T$ findings justify the use of $C T$ in acute head trauma. However, it should be done only when clinically indicated in order to reduce cost and avoid unnecessary irradiation.

\section{Recommendation}

1. In Eritrea, CT is still a scarce resource there is a need to develop and validate a simple set of clinical criteria for identifying patients with acute head injury who should undergo CT scanning.

2. A national large scale study of head injury and diagnostic testing is important to establish clinical screening criteria that indicate the need for imaging studies.

3. Appropriate medical care facilities including trauma centers need to be established at National Referral Teaching Hospitals with availability of modern CT scan.

\section{Reference:}

1. Jennet B, Epidemiology of head injury.J Neurol Neurosurg psychiatry 1996; 60:363-369.

2. Ake grenvik, Stephen MA, Ayres SM, Holbrook PR, Shaemaker WC; Management of Traumatic brain injury in the intensive care unit.Critical care 4th edition, 2000, 32226.

3. Paul E, marik, Joseph Varon and Todd trask .Management of head trauma chest 2002; 122; 9-711.
4. Royal Hospital for Neuro-disability, Brain injury-incidence and prevalence. Hospital Management Information Systems, Ministry of Health Eritrea data 30/10/09.

5. Jorge Merino-De villas ante, Juan M, Taveras.computerized tomography (CT) in acute head trauma. American journal of radiology 1976; vol 146, No 4.

6. Kimberly S, Quayle, David M, Jaffe, Nathan Kuppermann, Bruce A. Kaufman et al. Diagnostic test for children; when are head computed tomography and skull Radiographs Indicated. Pediatrics vol 99 No. 5 may 1997, pp e11.

7. Micelle J. Hayedcl, charles A. presion, Trevor J, mills, Samuel Luber, Erilk Blaudeau, and peter. MC Deblieux Indications for computed tomography in patients with minor head injury. N. Engl J. med 2000, 343: 1570-1571

8. GH yattoo and Amin Tabish the profile of head injuries and traumatic brain injury Deaths in Kashmir. Journal of trauma management and outcomes 2008, 2:5.

9. Kelly C. Bordignon, Walter oleschko-Arruda. CT scan findings in mild head trauma a series of 2000 Patients Arg. Neuro- psiquiatr, Vol. 60 no. 2 A Sao. Paulo June 2002.

10. Borczukp. Predictors of intracranial injury in patients with mild head trauma. Ann Emery Med 1995, 25:731-736.

11. M.O. Obajama, K.B. Jomah. W.O. Brackohuapa, W, Iddrisu. Computed Tomography features of head injury in Ghanaian children.

12. Asaleye C.M., famurewa O.C, komolafe E.O. et al. The pattern of computerized Topographic findings in moderate and severe head, injuries in ILE- IFE, Nigeria West African Journal of Radiology. April 2005 Vol 12 number.

13. Jeret JS, Man dell M, Anziska. B, et al. Clinical predictors of abnormality disclosed by computed tomography after mild head trauma. Neurosurgery 1993, 32:9-15

14. Robert A. Zimmerman, Larissa T. Bilanluk, Thomas Gennarelli, Derek Bruce et al . Cranial computed tomography in diagnosis and management of acute head trauma AM J. Roengenol 131:27-34, July 1978.

\section{Acknowledgments}

We thank Mr. Menghisteab Gaim from the continuing medical Education unit of the HRD-R of the Ministry of Health for his relentless support at the various steps of the research activity. We appreciate and feel grateful to the staff members of HMIS. 